Forthcoming, Cambridge Classic Arguments Series: the Knowledge Argument, S. Coleman, ed., Cambridge University Press

\title{
Acquaintance and Phenomenal Concepts
}

\author{
David Pitt
}

In this paper I defend the view that to know what it is like to experience a phenomenal property is just to be consciously acquainted with it, to experience it. ${ }^{1}$ Knowledge of what it is like is not knowledge that. It is not conceptual/propositional at all. It does not require thought, or the deployment of concepts. Nor is it knowledge what in the sense of, for example, knowing what time it is, or knowing what the positive square root of 169 is, which is also conceptual. And it is not some kind of know-how. It is, I will argue, simple acquaintance with, being familiar with, a phenomenal property. To know what a particular kind of experience is like is to be familiar with the phenomenal property or properties that characterize it; and to be familiar with such properties is just to experience them. Acquaintance is the fundamental mode of knowledge of phenomenal properties instantiated in experience, it is knowing what it is like; and it is simply experiencing. ${ }^{2}$

I will call this kind of knowledge "acquaintance-knowledge" (Conee calls it "phenomenal knowledge"). It is not the same as, and cannot be explained in terms of, knowledge

1 To my knowledge, this view of knowing what it is like was first proposed as a response to Jackson's thought experiment by Earl Conee (Conee 1994). Though I arrived at this view independently, much of what I have to say echoes what Conee says; and I reach some of the same conclusions about Jackson's argument. But I have different motivations and arguments. In particular, I think the view is inevitable given certain facts about the nature of concepts and the nature of qualitative experience, and given my views about the nature of thought and thinking. Moreover, I specifically address the "phenomenal concept strategy," which Conee does not do.

2 It might require attentive experience, or experience for more than a millisecond. I will set these complications aside for the time being. 
by acquaintance. Perhaps acquaintance-knowledge is what Russell meant by 'knowledge by acquaintance'. Nonetheless, there is an important distinction to be made between propositional knowledge based upon acquaintance and the acquaintance it is based on. The former involves thought and the deployment of concepts, whereas the latter consists merely in conscious experience. As I will use the phrase, knowledge $b y$ acquaintance with a phenomenal property $Q$ has the general form of knowing that $Q$ is like this (or that this is what $Q$ is like), where the demonstrative refers to an instance of $Q$ with which one is acquainted.

Knowledge by acquaintance that this is what $Q$ is like must in turn be distinguished from non-acquaintance-based knowledge that this is what $Q$ is like. Thoughts about phenomenal qualities one is not acquainted with can have the form this is what $Q$ is like, but such thoughts cannot ground knowledge by acquaintance. Since one cannot be acquainted with the experiences of others, one cannot gain knowledge by acquaintance of phenomenal properties their experiences instantiate. One may succeed in referring to an instance of $Q$ in experience not one's own, and one's thought that $Q$ is like this may be true. It may even count as knowledge. But it will not be knowledge by acquaintance, since acquaintance is lacking. Indeed, supposing there could be unconscious experience, and, hence, that there could be phenomenal properties instantiated in one's own experience with which one is unacquainted, one could think such a thought truly about one's own experience. And such a thought might count as knowledge. But, again, it would not count as knowledge by acquaintance, since acquaintance requires conscious experience.

Knowing what $Q$ is like is not knowing by acquaintance that $Q$ is like this, since it does not involve conceptualization or propositional thought at all. It is, as I said, constituted merely 
by acquaintance, by conscious experience. To know what uni tastes like, for example, is to experience the taste of uni. The most obvious way to do this is to taste some uni, though there are of course other ways - e.g., tasting something that is not uni but tastes just like it. Not knowing what uni tastes like requires never having tasted it (or something that tastes just like it), or having tasted it but being unable to remember it. But one can know what uni tastes like without knowing it is uni that tastes like that - that is, without knowing by acquaintance the proposition this is what uni tastes like. This kind of knowledge requires having the concept UNI; but one need not have that concept (or indeed any concepts at all) in order to taste uni and, thereby, to know what it tastes like. Hence, knowing what uni tastes like is not knowledge by acquaintance that uni tastes like this.

Nor is knowing what $Q$ is like knowing-what, in the sense of knowing what the positive square root of 169 is. To know the latter is to know that the positive square root of 169 is 13 , and that requires understanding and deploying the concept THIRTEEN. But there is no conceptual knowledge of what uni tastes like (just try explaining it to someone who has never tasted anything). The concept THE TASTE OF UNI is not like the concept THIRTEEN: grasping it does not enable one to know the nature of its referent.

Nor, finally, is knowing what $Q$ is like it know-how, as proponents of the Ability Hypothesis have claimed. Though knowledge of what it is like may enable certain capacities to recognize, imagine and remember, it is obviously not the same thing. The Ability Hypothesis is, to my mind, a prime example of one of the worst proclivities of twentieth-century analytic philosophy - viz., the attempt to reduce phenomena to their effects, in an effort to avoid facing up to difficult facts (such as, for topical example, the difficult fact of conscious qualitative 
experience). It is simply perverse. I will not discuss it further.

Knowing what $Q$ is like is simply being acquainted with it - experiencing it.

The consequences of this for Mary are obvious. When she leaves the black and white room (the Room) and sees puce for the first time, she knows what puce looks like simply in virtue of visually experiencing it. She becomes acquainted with something she had not been acquainted with before; and this acquaintance counts as knowledge all by itself. She does not gain propositional knowledge by acquaintance. What she comes to know does not depend upon her coming to be able to think that this is what puce looks like, or that puce looks like this. These are thoughts she was able to think (albeit not truly) while in her drab captivity. It does not require that she think anything at all. She can know what puce looks like without knowing that it is puce that looks like that - as she might if she were, like Nida-Rümelin's (1996) Mariana, released into a colorful antechamber containing no identifiable objects. She can know this without having the concept PUCE at all. Nor is Mary's new knowledge knowledge what, in the sense identified above, since there are no concepts the grasp of which enables Mary to know what she knows when she sees puce. And, though she becomes able to do things she could not do before her release, the knowledge she gains cannot be identified with any form of knowledge how. Thus, the only way to substantiate the intuitively correct claim that she gains new knowledge is to recognize that acquaintance per se, conscious experience, is its own kind of knowledge, knowing what it is like.

My argument for this will hinge on the rejection of "phenomenal concepts" (as that term is used by defenders of physicalism in response to Jackson's argument) and the phenomenal thoughts they would be constituents of (if they existed). None of the attempts to account for the 
change in Mary's epistemic situation by appeal to such special concepts and thoughts can succeed.

\section{Phenomenal Concepts}

A phenomenal concept, as I will use the term in this discussion, is a concept of a phenomenal property whose content is determined by the experience of the property, and which cannot therefore be possessed in the absence of experience of the phenomenal property it is the concept of. There can be concepts of qualitative experiences - e.g., RED, DARK, SWEET; but the contents of such concepts are not individuated by the properties they are concepts of. If there are no phenomenal concepts in this sense - concepts the grasp of which requires experience of the properties they are of - then there is no special conceptual knowledge of what it is like, no phenomenal thought. There is nothing one can think once one has experienced red that one could not think before experiencing it.

There are several ways in which the content of a concept could be individuated by experience of a phenomenal property. The experience could be taken to be a concept; it could be taken to be a constituent of the concept; the content of the concept could be individuated in virtue of referring to it; and the occurrence of the concept could be essentially tied to (caused by) experiences of the property. I have non-tendentious and tendentious reasons for thinking that none of these can work

There are intuitively good reasons for thinking that concepts could not be percepts or images. Concepts and percepts are fundamentally distinct kinds of mental items. For one thing, we can think about, and have concepts for, things that cannot in principle be perceived (and, hence, not imagined), such as transfinite ordinals, ten-dimensional spaces and (non-actual) 
possible worlds. We can also think about, and have concepts for, things that can be perceived, but which cannot be imagined, such as chiliagons and ten-thousand-six-speckled hens. If we can think about things that cannot be perceived or imagined, then we have concepts of those things. But if we cannot perceive or imagine them, we do not have percepts or images of them. Hence, our concepts of them cannot be percepts or images of them.

Moreover, it seems obvious that perceiving and imagining are possible without thinking as, for example, when one absent-mindedly takes in one's perceivable environment, enjoys one's phosphenes, or listens to Bartók in one's head. These are, apparently, activities one can engage in without deploying concepts at all. And it certainly seems possible that there could be nonhuman creatures capable of perceiving and imagining but not of conceptualizing (and even vice versa), as well as that there could be (maybe there are) humans who can do one but not the other. A deeper, but still, I think, intuitive reason for thinking that concepts are not percepts or images is that concepts (i.e., conceptual contents) must be thinkable, while percepts and images are not. It is nonsense - a category mistake - to say that what I was thinking (or part of what I was thinking) was the smell of lavender or the sound of a distant trumpet, or that the concept I was entertaining was rose-tinted or amused. It is true that I can think about these things, but only in the sense that I can have otherwise-content-individuated concepts that refer to them. Concepts (their contents) must be things capable of being thought - in the course of thinking a complete thought of which they are constituents, or merely entertained - simply had in mind or considered.

I have a tendentious explanation for all of this. It is that thinking is a distinctive kind of experience, and that distinct kinds of experience are distinguished by distinct kinds of phenomenology. Thinking is not the same kind of experience as seeing, hearing, smelling, 
tasting, and so on. So thinking must have its very own brand of phenomenology $-\mathrm{a}$ phenomenology which I have elsewhere (Pitt 2004) characterized as proprietary, distinctive and individuative. Thinking is a mode of experiencing, and (I take this to be untendentious) experiential modes in general are distinguished phenomenally. Vision, audition, olfaction, gustation, etc. are modes of experiencing, and each is constituted by its own proprietary kind of determinable phenomenology (visual, auditory, olfactory, gustatory, ...). Hence, there is a proprietary determinable phenomenology for thought - what I have called (Pitt 2004) cognitive phenomenology (conceptual or propositional phenomenology will do as well).

I have both epistemic and metaphysical reasons for believing that there is a proprietary, distinctive and individuative phenomenology of thought (that is, of thought content). Briefly, the epistemic reason (Pitt 2004) is that there is available to us a mode of access to the contents of our conscious occurrent thoughts - viz., introspective and non-inferential - that would not be available to us if occurrent conscious thought contents were not distinctively presented to us in conscious experience. In general, discriminatory non-inferential introspective awareness of occurrent conscious mental states requires that the states accessed be differentiated in consciousness - that is, they must be introspectively distinguishable and identifiable as the states they are. (This is analogous to the role that distinguishability and identifiability of objective properties plays in purely perceptual discrimination.) But differentiation in consciousness is entirely a matter of difference of phenomenology. Thus, we can be non-inferentially introspectively aware that we are experiencing a pain, and not a smell or a sound, that the pain is burning, and not achy or slashing, or that it has gotten worse, because pain experiences have proprietary, distinctive, individuative phenomenologies. And we can be non-inferentially 
introspectively aware that we are thinking, and not feeling pain or hearing a sound or smelling a smell, and that we are thinking about metamathematics, and not about ice cream or international trade agreements. But if conscious thoughts can be thus discriminated from other conscious states (or events) and identified as the thoughts they are, introspectively and non-inferentially, they too must have proprietary, distinctive, individuative phenomenologies.

This is a transcendental argument: a certain kind of access to conscious occurrent thought content is possible; but it would not be possible if there were no proprietary, distinctive, individuative phenomenology of thought; hence, there is such phenomenology.

The metaphysical reason (Pitt 2011) focuses on the fact that conscious states in general are, qua conscious, phenomenally individuated. What distinguishes, for example, conscious smells from conscious sounds is their distinctive kinds of phenomenologies (olfactory and auditory). Hence, if conscious thoughts are not conscious sights, smells, sounds, ..., then they must have their own kind of phenomenology that constitutes their determinable phenomenal kind. ${ }^{3}$ And if the thought that tungsten is a rare metal is a different thought than (has a different content from) the thought that robots have invaded the pantry, then, like the sound of a cymbal and the sound of a sneeze, they must have different determinate phenomenologies.

If this is correct (and I assure you, it is), then one could no more think sounds or colors or smells than one could smell sounds or colors or thoughts. These kinds of experiencing are constituted by the instantiation of metaphysically radically distinct sorts of phenomenal

${ }^{3}$ Obviously this requires an adjustment to my claim that there are no phenomenal concepts - i.e., that no concepts individuated by phenomenology. It has to be restricted to noncognitive phenomenology, in light of my view that conceptual contents are cognitivephenomenal. Though I still think cognitive-phenomenal conceptual contents are not referentially individuated: it is possible to introspectively misidentify a concept. 
properties. There can be no cross-modal experiences. One cannot experience olfactory percepts or images in the way one experiences colors, or experience colors in the way one experiences sounds. Seeing is not smelling or hearing. Confused interpretations of the phenomenon of synesthesia aside, it is absolutely impossible to smell colors, hear flavors, etc. If thinking is a distinctive fundamental kind of experience, one cannot think any of these things either. Just as one can only hear sounds and smell smells, one can only think - i.e., cognitively experience thoughts (and their constituent concepts). ${ }^{4}$

\section{Phenomenal Immiscibility}

I also think it is untendentious and intuitively clear that experiences of different phenomenal modalities cannot mix. Not only can one not smell colors or taste thoughts, there cannot be conscious states of any of these phenomenal kinds partially consisting of instantiations of different kinds of phenomenology. That is, there cannot be a sound a part of which is a smell, or a sight a part of which is a taste. There may be experiences that have sounds, smells, sights and tastes as constituents (as for example one's total experience at a given moment). But the constituents remain metaphysically independent. Experiences of different modalities cannot combine the way experiences of the same modality can - for example, in the synergistic way the taste of chocolate and taste of orange combine, or the way the sound of middle-C on a trumpet followed by the sound of a drum-roll can be temporal parts of a single auditory experience. The orange-chocolate taste is still a taste; and the trumpet-drum sound sequence is still a sound.

4 The same reasoning can be used to show that external objects cannot be conceptual contents either. One could no more think a set of possible worlds, or water, or one's refrigerator, than one could think a smell or a sound. These are things of the wrong kinds; they are not even phenomenal properties. 
There can be no orange-trumpet taste (or sound), or chocolate-drum-roll sound (or taste). I call this general fact the Principle of Phenomenal Immiscibility. ${ }^{5}$

\section{The Phenomenal Concept Strategy}

The phenomenal concept strategy in defense of physicalism is to claim that though Mary gains new concepts, and, hence, new knowledge upon her release, she does not learn any new facts. What happens is that she relearns old facts in new ways. On one account, the new concepts she gains are content-individuated by percepts or images of the previously unperceived/unimagined properties she nonetheless had complete scientific knowledge of in the Room. These might be "quotational" phenomenal concepts in the style of Balog (1994), Block (2006) and Papineau (2002), which in some way "contain" samples of the phenomenal properties they are concepts of. Or they might be concepts whose contents are individuated by broadly referential relations to the properties they are concepts of, as on Sainsbury and Tye's (2011) “originalist” view, or Evans’s (1982) and McDowell’s (1984) object-dependent sense view. On another account, Mary acquires what Loar (1997) calls recognitional concepts, which bear a special relation to experiences one has had, in virtue of which they are "triggered" by subsequent experiences of the same kind. These would be analogous to, say, the concepts of middle $\mathrm{C}$ and the B-flat below it that people with perfect pitch have: they hear the pitch; they automatically token the concept MIDDLE C or B-FLAT BELOW MIDDLE C, and on the basis of this come to know what the pitch is.

5 The same reasoning can be used to show that external objects cannot be constituents of conceptual contents either. One's thought could no more contain Mont Blanc as a constituent than it could the sound of a trumpet. The Principle of Phenomenal Immiscibility is thus in the spirit of Frege's principle that only senses can be constituents of senses. 
Beyond the obvious problem that all of these accounts build in more or less intimate relations to conscious qualitative properties that Mary had not experienced before her release, and so still face the problem they were supposed to finesse (i.e., the metaphysical status of those properties), these strategies are all ruled out by the facts about experience, concepts and thought detailed above.

The Principle of Phenomenal Immiscibility rules out quotational phenomenal concepts. Concepts are cognitive-phenomenal experiences; colors (sounds, smells, ...) are not. So colors cannot be constituents of concepts. There is no special puce-percept-or-image-containing concept that Mary acquires upon experiencing puce for the first time. It is impossible for such things to exist. What is not impossible is for there to be a phenomenal sample (a percept or an image) that one is thinking about - applying a concept to. But the content of the concept cannot involve non-cognitive phenomenology, any more than a Fregean sense could contain a mountain, or a color, or the sound of a distant trumpet. These are the wrong kinds of things to be thought constituents. For me, senses (thought contents) are cognitive phenomenal types (see Pitt 2009), and they (their tokens) can only be composed of (tokens of) cognitive phenomenal types.

Such concepts are also ruled out because their contents, not being cognitive phenomenal, cannot be thought - i.e., cognitively experienced.

For essentially the same reasons, I deny that there are concepts whose contents are individuated by their referential relations to percepts or images (or to anything else, for that matter), whether these be Kaplanian indexical concepts, Evans-McDowellian referentiallyindividuated-sense concepts or Sainsbury-Tye originalist concepts. Anything non-cognitivephenomenal is the wrong kind of thing to be a conceptual content individuator. Conceptual 
contents are cognitive phenomenal types, individuated entirely phenomenally, and phenomenal properties in general are not individuated relationally. The pain of a sunburn is not per se different from the pain of a windburn or an iceburn because it was caused by the sun and not by the wind or ice. The same holds for cognitive experiences. The demonstrative concept THIS PAIN does not change its cognitive content depending upon its referent, or its origin. THIS PAIN applied to a burning pain is the same concept as THIS PAIN applied to an ache. And the thoughts I DO NOT LIKE THIS PAIN thought of the burning and the aching are the same thought. They are the same thought, thought about different things.

In fact, I do not think that any indexical concepts are content-individuated referentially. If you and I both think I HATE THAT IDIOT, we are thinking the same thought, even if the referents of our concepts I and THAT IDIOT are different. We deploy the same concepts, I and THAT IDIOT. The fact that my token of I must refer to something different from your token, or that our tokens of THAT IDIOT in fact refer to different idiots, does not make them different concepts. (Any more than my hat becomes a different hat when you put it on.) It is not in general true that possible difference in truth value entails difference in content. The expression 'the democratic presidential nominee' (and the concept it expresses) has a different referent now than it did in 2012, and the expression 'the democratic presidential nominee in 2016 ' has a different referent in other worlds. But it does not follow that it has changed its meaning since 2012, or that it means something different in other worlds. I do not think there is any good reason to think that there is a principled difference between such expressions and indexicals. 
They differ only in the scope of the context with respect to which their referents are determined. ${ }^{6}$

Also for these reasons, I reject Loar's recognitional concept strategy. I do not think that a person with perfect pitch has a different concept of middle $\mathrm{C}$ from me. The fact that he instantly identifies the pitch when he hears it does not make his concept different from mine. What is different between us is his automatic and infallibly correct application of it. His concept of MIDDLE C is like my concept RED. I recognize red on sight. But I do not think I have a different concept from someone who is color blind, or totally blind.

Concepts are constituents of thoughts. Thinking is a metaphysically distinct kind of experience from seeing. Hence it is possible for one to occur without the other. So it is possible for the congenitally blind to think THIS IS RED of something they are touching. And what they think is exactly the same as what I think when I think THIS IS RED of something I see. When it comes to saying what red is, Mary is as conceptually competent as I am. If you ask Mary to tell you about red, she will tell you exactly what you would tell her if she asked you to tell her about red. The differences between us are not conceptual, they are perceptual. Blind people can have exactly the same concept of red as sighted people. The fact that sighted people know how red things look and blind people do not does not entail that they have different concepts.

If one recognizes thinking as a fundamental kind of experience, irreducible to and immiscible with any other fundamental kind of experience, it becomes very clear that not everything that is happening in the conscious mind can be treated as part of what one is consciously thinking. I may have visual experiences Mary does not have, but it does not follow

6 This view of indexical (including demonstrative) concepts is defended in Pitt 2013. It is further developed in my forthcoming book The Quality of Thought. 
that I have cognitive experiences she does not have. To be sure, I know propositions she cannot know. But, as I have been arguing, this is not because I can think things she cannot think. I may be able to think things truly that she cannot think truly - as, for example, that this thing is puce. In this sense I may be capable of knowing things Mary cannot know. But it is not in virtue of my being able to deploy concepts she cannot deploy. It is simply a mistake to assimilate the perceptual differences between us to differences in what we can think. It is a mistake to assimilate all knowledge to knowledge that. The various kinds of experiencing must be kept strictly separate in our theories of mental content.

The knowledge that I can have that Mary cannot have is knowledge of what it is like to see chromatic colors, acquaintance-knowledge of particular phenomenal properties.

\section{Tye on Knowing What It Is Like}

Michael Tye (2011) argues that being acquainted with a phenomenal property (which I assume is what he means by "know[ing] the phenomenal or subjective character of an experience") cannot be the same as knowing what the property (the experience) is like, because of the logic of knowledge-wh statements. For example, according to Tye the following argument is invalid:

1. Mary knows the phenomenal character of the experience of seeing puce.

2. The phenomenal character of the experience of seeing puce is what it is like to see puce. Therefore,

3. Mary knows what it is like to see puce.

It is invalid because it has the same form as the following obviously invalid arguments ${ }^{7}$ : conclusions.

7 Tye presents his examples as consistent triples of the premises and the denials of the 
1a. Samantha knows the color red.

1b. The color red is what my favorite color is. Therefore,

1c. Samantha knows what my favorite color is.

2a. Paul knows Ann.

2b. Ann is whom Sebastian loves. Therefore,

2c. Paul knows whom Sebastian loves.

His explanation of the invalidity of these arguments is that it is in general not true that whexpressions can be replaced with co-referring expressions in intensional contexts, salva veritate.

But these arguments are invalid because they equivocate, not because $w h$-expressions cannot be replaced with co-referring expressions within the scope of an intensional verb. The word 'know' is being used in different senses in their first premises and their conclusions. In the premise-sense, to 'know' is to be acquainted with (to bear a certain relation to a property); in the predicate-sense, to 'know' is to know that (to bear a certain relation to a proposition). It is easy to see why these arguments are invalid if we disambiguate:

1a'. Samantha is acquainted with the color red.

1b. The color red is what my favorite color is. Therefore,

$1 c^{*}$. Samantha knows what my favorite color is. That is, Samantha knows that my favorite color is red.

2a'. Paul is acquainted with Ann.

2b. Ann is whom Sebastian loves. Therefore,

2c*. Paul knows whom Sebastian loves. That is, Paul knows that Sebastian loves Ann.

If we read 'know' in the conclusion in the acquaintance sense, the arguments are valid:

1a'. Samantha is acquainted with the color red. 
1b. The color red is what my favorite color is.

Therefore,

$1 c^{\prime}$. Samantha is acquainted with what my favorite color is.

2a'. Paul is acquainted with Ann.

2b. Ann is whom Sebastian loves.

Therefore,

$2 c^{\prime}$. Paul is acquainted with whom Sebastian loves.

These arguments are valid because 'acquaintance' contexts are extensional.

If $1 c^{\prime}$ and $2 c^{\prime}$ are a bit awkward, it is because $1 b$ and $2 b$ are a bit awkward. They are awkward ways of saying, respectively, that red is my favorite color and that Ann is the person Sebastian loves. (Perhaps they are best thought of as employing focus or topicalization.) If we adopt the less awkward phrasing, it is even clearer that the arguments are valid:

1a'. Samantha is acquainted with the color red.

$1 b^{\prime}$. Red is my favorite color.

$1 c^{\prime}$. Samantha is acquainted with my favorite color.

$2 \mathrm{a}^{\prime}$. Paul is acquainted with Ann.

$2 b^{\prime}$. Ann is the person Sebastian loves.

$2 c^{\prime}$. Paul is acquainted with the person Sebastian loves.

Of course 'acquainted with' can be used to describe a relation one stands in to propositions, as in "I am acquainted with the continuum hypothesis" (I know what it is; I know that it is that there are no numbers between $\aleph_{0}$ and $2^{\boldsymbol{N}_{0}}$ ) or "I am acquainted with your dietary restrictions" (I know what they are; I know that they are that you detest celery). But to interpret the conclusions in this way is to equivocate on the two senses of this phrase, for surely it is not being used in this sense in the first premises. It does not follow from 1a' and $1 \mathrm{~b}^{\prime}$ that Samantha is acquainted with the fact that my favorite color is red, or from $2 a^{\prime}$ and $2 b^{\prime}$ that Paul is acquainted with the fact that Sebastian loves Ann. 
I conclude that there is no logical reason not to identify acquaintance-knowing with knowing what it is like.

\section{Physicalism}

The account of Mary's epistemic situation that I am promoting is neutral with respect to the ontological status of the properties she becomes acquainted with upon her release. ${ }^{8}$ Nothing I have said entails anything about the metaphysical nature of qualia.

Though I have argued that acquaintance-knowledge is knowledge of the intrinsic properties of experiences, nothing follows about the nature of those properties. Acquaintanceknowledge is a mode of knowing a phenomenal property that requires that the property be directly experienced. Mary does not have this kind of knowledge of phenomenal puce, because she has never experienced it. Without acquaintance there can be no knowledge of the nature of phenomenal properties, no knowledge of what it is like to experience them, and no knowledge by acquaintance of them (knowledge that this is what $Q$ is like).

However, though acquaintance-knowledge is the fundamental mode of knowing that a phenomenal property is like, there can be acquaintance-knowledge of non-phenomenal properties as well. In such cases acquaintance is not the only way to come to know the nature of the properties; but it still constitutes a different mode of knowing. For example, one may know have complete theoretical knowledge of what an icosagon is, but not be acquainted with the property of icosagonality, because one has never perceptually encountered an instance of it.

Suppose Mary is in such a situation. Though she is theoretically geometrically omniscient, there are no instances of icosagonality in the Room. There are no icosagonal objects,

${ }^{8}$ Conee $(1994,147)$ draws the same conclusion. 
and she has never bothered to draw an icosagon. So she has never perceived icosagonality. Moreover, she, like the rest of us, cannot construct one in her imagination.

[insert image]

Though she knows what icosagonality is (twenty-sidedness), she is not acquainted with it. If one day she draws an icosagon or Googles 'icosagon', she will become perceptually acquainted with the property of icosagonality. But we cannot conclude from this that icosagonality is not a physical property (i.e., a property that physical objects can instantiate). Surely it is. What she lacked before she drew an icosagon was acquaintance-knowledge of the shape. Nothing follows about the nature of the property she has gained acquaintance-knowledge of.

The same is true of acquaintance with physical objects. If Mary has never seen Lake Balaton, she is not perceptually acquainted with it, in spite of her physical omniscience. Even if she has seen pictures of Lake Balaton, or imagined it, if she has never seen it, she is not perceptually acquainted with $i$. She is not in a position to think, truly, this is lake Balaton. If, when she is released, she goes to Hungary and visits Lake Balaton, she will gain something she 
could not have had in the Room - acquaintance-knowledge of Lake Balaton. And she will thereby become capable of knowledge by acquaintance of it. It does not follow that lake Balaton is not a physical object.

From the fact that theoretically physically omniscient Mary cannot have a particular kind of knowledge while in the Room, we cannot conclude that any knowledge she gains upon her release is knowledge of non-physical facts. She gains a new mode of knowing certain things, which may themselves be either physical or not.

\section{Retaining Acquaintance-Knowledge}

When Mary leaves the Room, she gains acquaintance-knowledge of chromatic colors even if she cannot apply her color concepts to them or identify them by name. Visually experiencing them counts as knowing them, in the only way in which it is possible to know the nature of phenomenal properties, what they are like. At the instant Mary sees a color, she knows what it is like to see it. And as long as she is looking at it, she retains this knowledge. When she is not experiencing a color (perceptually or imaginatively), I maintain, she does not know what it looks like. If she is not seeing it or imagining it, she does not acquaintance-know it (and, hence, she does not by-acquaintance know it). Retention of the capacity to imagine or recognize a phenomenal property is not retention of knowledge of what the property is like. It is retention of the capacity to know what it is like. The capacity to know is not knowing, any more than the capacity to whistle is whistling. We may say that Mary continues to know what puce looks like while she is not experiencing it, just as we say that someone continues to believe that $5+7=12$, or to be a good whistler, while asleep. But it is not literally true. ${ }^{9}$

\footnotetext{
9 I develop this point a bit more in Pitt 2016.
} 
Suppose Mary, still in the Room, has never tried to imagine puce, but, through some neurological fluke, could do so if she tried. If she tries, she will come to know what puce looks like. But before she imagines it, she does not know what it looks like, because she has never been acquainted with it, even though she was capable of imagining it. Hence, having the capacity to imagine puce is not knowledge of what it is like. Moreover, having the capacity to (imaginatively) remember what puce looks like does not count as knowing what it is like either. For this is just the non-flukish capacity to imagine it. Having the capacity to remember a phenomenal property does not count as knowing what it is like any more than having the capacity to non-memorially imagine it. Again, the capacity to know what it is like - the capacity to experience it - is not the same as knowing what it is like - experiencing it. If Mary is asked if she knows what puce looks like, she will not be able to give a positive answer unless an until she can re-experience it. She may think she does, because she thinks she can; but if she cannot, then she does not know. If she tries and fails, she must admit that though she once knew what puce looks like, she no longer does. And this is because to know it is just to experience it, to be acquainted with it. She would have to remind herself what it looks like by looking at a sample of it. Acquaintance-knowledge of phenomenal properties (like all genuinely mental states $^{10}$ ) exists only in the conscious moment. If you know what puce looks like, it is not because you can imagine it. You know what puce looks like when you imagine it (or see it). If you can imagine it, then you can know it. But 'can' does not imply 'is'. Being able to know what it is like is not knowing what it is like, any more than being able to whistle is whistling.

${ }^{10}$ I realize that this is like announcing to your therapist that you are from another planet as you are leaving your session. I do have reasons for believing this controversial claim. They are discussed in detail in my forthcoming book. 


\section{REFERENCES}

Balog. K. 1999. "Conceivability, Possibility, and the Mind-Body Problem,” Philosophical Review 108: 497-528.

Block, N. 2007. "Max Black's Objection to Mind-Body Identity,” in T. Alter and S. Walter, eds., Phenomenal Concepts and Phenomenal Knowledge: New Essays on Consciousness and Physicalism, Oxford University Press.

Conee, E. 1994. “Phenomenal Knowledge,” Australasian Journal of Philosophy 72: 136-150.

Evans, G 1982. The Varieties of Reference, Oxford University Press.

Loar, B. 1997. "Phenomenal States," in N. Block, O. Flanagan, G. Güzeldere, eds., The Nature of Consciousness, MIT Press.

McDowell, J. 1984. “De Re Senses,” Philosophical Quarterly 34: 283-294.

Nida-Rümelin, M. 1996. "What Mary Couldn't Know: Beliefs About Phenomenal States," in T. Metzinger, ed., Conscious Experience, Schöningh/Imprint Academic.

Papineau, D. 2002. Thinking About Consciousness, Oxford University Press.

Pitt, D. 2004. "The Phenomenology of Cognition, Or, What Is It Like to Think That P?", Philosophy and Phenomenological Research 69: 1-36.

Pitt, D. 2009. “Intentional Psychologism,” Philosophical Studies 146: 117-138.

Pitt, D. 2011. "Introspection, Phenomenality and the Availability of Intentional Content," in M. Montague and T. Bayne, eds., Cognitive Phenomenology: New Essays, Oxford University Press.

Pitt, D. 2013. "Indexical Thought," in U. Kriegel, ed., Phenomenal Intentionality: New Essays, Oxford University Press.

Pitt, D. 2016. “Conscious Belief,” Symposium on Tim Crane's Aspects of Psychologism, Rivista Internazionale di Filosofia e Pscologia 7: 121-26.

Pitt, D. Forthcoming. The Quality of Thought, Oxford University Press.

Sainsbury, M. and Tye, M. 2011. "An Originalist Theory of Concepts," Proceedings of the Aristotelian Society 85: 101-124.

Tye, M. 2011. “Knowing What It Is Like," in J. Bengson and M. Moffett, eds., Knowing How: 
Essays on Knowledge, Mind, and Action, Oxford University Press. 